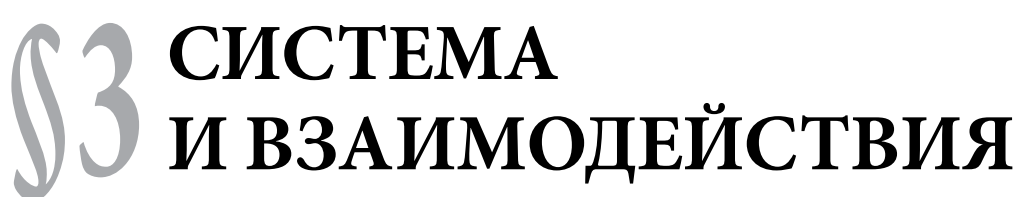

Чернядьева Н.А.

\section{ОСОБЕННОСТИ ПОЗИЦИИ США ПО ВОПРОСАМ БОРББЫ С ТЕРРОРИЗМОМ В НАТО И ВО ВЗАИМООТНОШЕНИЯХ С ЕС}

\begin{abstract}
Аннотация. Предметом исследования является место США в системе международного взаимодействия в деле борьбы с терроризмом в рамках международной организации НАТО и договорного сотрудничества с Европейским Союзом. Особое внимание уделяется начиональным американским правовым особенностям понимания феномена терроризма, которые обуславливают специфику контртеррористического поведения в рамках НАТО и сложности взаимоотночения между ЕС и США по вопросам международной безопасности, в частности: отсутствие разработанной концепции терроризма как международно-политического явления, предпочтение военному способу реакции в ответ на теракты. В статье проведено системное исследование, основанное на применении структурно-функционального метода, позволивщего установить общее и особенное в подходах $\kappa$ формированию контртеррористической политики США, ЕС, НАТО. Основные выводы исследования заключаются в следующем. В НАТО, как и в правовой системе США, наблюдается тендениия представления терроризма как явления, требующего мер военного воздействия. В работе отмечено, что НАТО, как военный альянс не приспособлен к профессиональному правовому противодействию и расследованию преступлений террористического характера. В свлзи с этим автор делает вывод, что правильное участие этой организачии в антитеррористической сфере представляется только как локального субъекта снятия острого политического кризиса. Европейский Союз, в отличие от США, в большей мере демонстрирует мнение, что терроризм - явление уголовно-правового порядка, чем вопрос политической борьбы государственного уровня. Между ЕС и США в вопросах контртеррористической борьбы отмечаются существенные концептуальные расхождения.
\end{abstract}

Ключевые слова: международнал безопасность, терроризм, США, НАТО, Европейский Союз, международнал преступность, политическое насимие, международное гуманитарное право, международное антитеррористическое право, террористическал угроза. 
Abstract. The article explores the place of the United States in NATO and the contractual cooperation with the European Union on combating terrorism. The author pays special attention to the peculiarities of the American legal understanding of the phenomenon of terrorism, which cause specificity conduct counterterrorism within the framework of NATO and the complexity of the relationship between the EU and the United States on international security issues. This study is based on the use of structural-functional approach, which allows setting the general and special in approaches towards the formation of the US, EU, and NATO counter-terrorism policies. The following conclusions were made: the author underlines tha there is a trend of presentation of the phenomenon of terrorism in both, NATO and US legal system, which requires military action. It is noted that NATO, as a military alliance, is not adjusted to the professional legal counteraction and investigation of terrorist crimes. In this regard, the author concludes that the appropriate participation of this organization in the sphere of anti-terrorism appears only as a local entity in relieving of the acute political crisis. The European Union, unlike the United States, demonstrates the opinion that terrorism is rather the phenomenon of criminal-legal norms than the question of the political struggle at the state level. The significant conceptual differences are determined between the EU and the US regarding counter-terrorism actions.

Key words: Terror threat, International anti-terrorism legislation, International humanitarian law, Political violence, International crime, European Union, NATO, United States, Terrorism, International security.

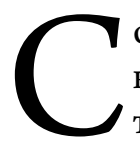

оединенные Штаты Америки, относясь к разряду ведущих межАународно-политических игроков, претендуют на мировое лидерство во всем, что касается гмобальной системы безопасности. [7, p. 76] Специальный советник генерамьного юрисконсульта Министерства Обороны США Аж. ГолАсмит, в том числе в связи с проблемой терроризма, назвал США «мировым жандармом, ... с политической волей на подавление непокорных угнетатемей».[13, p. 89-93] При этом США жестко придерживаются идеи допустимости соверше-

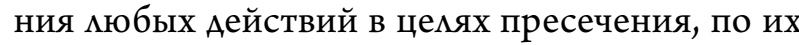
мнению, Аюбых преступлений против государственных интересов, понимаемых Аостаточно широко. Соединенные Штаты расценивают, что их мировые «полицейские полномочия» Аают им право на это.[2, с. 9]

А^я правовой системы США присуща соАержательно очень широкая концепция терроризма, предполагающая возможность включить в это понятие мюбое политическое насилие, как внутригосударственного, так и интернационального пиана. В связи с этим становится объяснимым, что борьба с терроризмом предполагается осуществцяться США преимущественно военными методами, с использованием армейских ресурсов и предпочтительно в превентивнозарубежном варианте. По словам Ч. Фримана, посла США, руководителя Projects International Inc., «Мы по привычке отвечаем на всевозможные вызовы военным позированием... ». [12]

Кроме того, такой подхоА объясняет Аоктринальную и прикладную (правоприменительную) проблему разграничения действия норм межАународного гуманитарного и антитеррористического права в США, проявляющуюся, в том числе, и в том, что по факту США в своих антитеррористических операциях не придерживаются в полной мере ни тех, ни Аругих правил. В целом, можно сказать, что США в большей мере считают терроризм явлением не криминальным, требующим правовой реакции, а политическим. $[15$, p. 455]

Сложившая американская концепция терроризма влечет за собой специфическую позицию США в межАународном сотрудничестве в сфере безопасности.

Рассмотрим, каким образом влияют США на правовую позицию по борьбе с терроризмом НАТО - военного союза, согласно положениям ст. 3,5 Устава, ориентированного на ведение армейских операций в цемях поААержания мира и безопасности, предотвращения (или прекращения) вооруженного нападения на государство участник Альянса. [6]

Известно, что США принаАлежит опреАеляющее место в структуре НАТО. А Оливеро показал, что в 2008 г. на Аолю США приходилось $48 \%$ мировых военных расходов, в то время как его ближайшие партнеры по Альянсу придерживались значительно более скромных цифр: Великобритании принадмежали 5\%, Франции $4 \%$, Германии - 3\%, Италии - $2 \%$.Нидерландам, Швеции и Испании, всем вместе - $3 \%$. Итальянский исследователь такое положение характеризует как «глобальное позитивное доминирование» США. Отказ большинства европейских 
госуаарств от коренного увеличения вложений в бюАжет НАТО, А. ОАиверо объясняет тем, что Аополнительные инвестиции не изменят сложившейся практики оАностороннего, мидирующего поведения США в Альянсе. [15, р. 455] Аействительно вопреки отрицательной реакции Франции, ФРГ, иных госуАарств-участников, США осуществики по своей инициативе, в рамках операций НАТО, поА преАлогом войны с межаународным терроризмом, военные операции в Ираке, Аивии.

Ведущая роль США прослеживается и формировании положений концепции противодействия терроризму в НАТО, точнее в несистемности, Аоктринальной неоформленности и смешения норм уголовно-правового реагирования и межАународного гуманитарного права.

В 2002 г. в Праге, впервые были сформулированы новые, антитеррористические направления деятельности НАТО: « ... главы государств и правительств стран НАТО выразили решимость сАерживать из-за границы, в том числе, террористические, и защищать насекение, территорию и войска стран-чиенов от подобных нападений». [5] Амя реализации этого быц утвержАен Пражский пакет мер, призванный преобразовать НАТО Аля противодействия вызову терроризма, вкАючивший в себя Военную концепцию защиты от терроризма.

Эта новая концепция предполагает готовность Североатлантического союза противостоять террористическим нападениям или угрозе подобных напаАений, руковоАить или преАоставмять поААержку антитеррористическим операциям, оказывать содействие национальным властям при миквидации послеАствий терактов, на разовой основе оказывать содействие операциям, проводимым Аругими межАународными организациями ики коалициями, в которых участвуют члены НАТО и проводить военные операции против террористических групп и их сил и среАств, в строгом соответствии с принципами ООН и межАународными правовыми нормами, вкцючая межАународное гуманитарное право и права человека. [5]

В 2006 г. Североатлантический союз принял решение о том, что террористический акт, совершенный негосударственными субъектами, требует выполнения обязательства о комлективной самообороне. [5] Тем самым НАТО вышел за пределы межгосударственных отношений, в одностороннем поряАке распространим Аейст- вие правии военного союза на несимметричные конфмикты, в которых статусом воюющей стороны обладает только один участник.

Специальной теории, стратегии, вкмючающей доктринацьные согласованные всеми участниками разработки проблемы международного терроризма в НАТО нет. Таким образом, можно саелать вывоА, что в НАТО, как и в правовой системе США, имеется констатация необхоАимости борьбы с межАународным терроризмом, понимание того, что это явмяется оАной из основных угроз межАународному миру и безопасности, но нет четкого преАставления о сущности Аанного феномена, наблюдается тенденция преАставления терроризма как международнополитического явмения, требующего мер военного возАействия.

Следует отметить, что НАТО, как военный альянс не приспособлен к профессиональному правовому противодействию и расследованию преступиений террористического характера. Поэтому правимьное участие этой организации в антитеррористической сфере преАставмяется Аостаточно узким: только как мокального субъекта снятия острого политического кризиса. Причем, Аумается, что все Аействия подобного рода Аолжны осуществляться в правовом поле (так как речь иАет о мерах по противодействию преступному поведению) и поА безусловным руководством и контролем компетентного межАународного органа, уполномоченного именно на правовое реагирование на акты террора в глобальном масштабе, прежле всего, Совета Безопасности ООН.

То, что НАТО не может признаваться межАународной организацией - полноценным участником антитеррористической борьбы заявляли на уровне ООН ряА госуаарств-членов. Например, при утвержАении проект резолюции о мерах по миквидации международного терроризма, [9] представители Сирии, Венесуэлы, Кубы, Никарагуа высказали свои возражения против упоминания НАТО в пункте 24 преамбулы Резолюции, в которой названы все межаународные организации (инструменты), веАущие борьбу с терроризмом. [16, р. 7-8]

Еще один аспект Аанной темы - это оценка содержательной близости поАходов США и его ближайшего союзника - Европейского Союза на сущность феномена «терроризм» и перспективы совместной борьбы с ним.

Среди международных организаций и третьих госуАарств, при безусловном приоритете 
роли ООН в деле борьбы с терроризмом, ЕС отАает преАпочтение сотрудничеству с США как наиболее эффективному и стабильному партнеру. [1, с. 11-12] Так, Генеральный прокурор США Э. ХомАер в 2013 г. заявия: «США и Европа находятся переА мицом общих угроз, что требует развития еАиной политики ААЯ противодействия им. Мы Аолжны учиться Аруг у Аруга. И хотя нас разделяет океан, мы знаем, что тот, кто жекает причинить змо США, намерен сАелать это и в отношении наших европейских союзников». [3]

ОАним из базовых Аокументов, в котором выработаны общие подходы к проблеме межАународного терроризма, стала Аекларация о борьбе с терроризмом, принятая на саммите США и ЕС в Шенноне (26 июня 2004 гоАа). [17] В пункте 1.1 Аекларации стороны берут на себя обязательство подАерживать веАущую роль $\mathrm{OOH}$, ее Генеральной Ассамблеи и Совета Безопасности, сотрудничать с Контртеррористическим комитетом ООН и вносить свой вклаА в программу $\mathrm{OOH}$ по наркотикам и преступности. Пункты 2.1-2.11 посвящены расширению сотрудничества сторон в противодействии финансирования террористической Аеятельности, включая координацию на уровне США - ЕС, укрепление Группы разработки финансовых мер борьбы с отмыванием денег (ФАТФ) и защиту свидетелей. В пунктах 3.1-3.12 стороны берут на себя обязательства о расширении взаимодействия межАу правоприменяющими органами, в том числе в рамках Соглашения межАу США и ЕС об экстраАиции и взаимной правовой помощи.

ОАнако стоит отметить, что антитеррористические отношения США и ЕС не могут считаться безупречными и абсолютно согласованными. Неоднократно США выражали неудовольствие решениями и практическими направлениями Аеятельности ЕС в Аанной сфере. Так, резкой критике со стороны США поАвергся отказ Италии и Германии выАать США как террориста мидера курАской партии А. ОАжалана, прибывшего в ФРГ Аля мечения. [15, p. 456] США считают, что антитеррористические действия ЕС менее решительные, более мягкие, чем их собственные: «...европейцы скмонны управмять терроризмом так же, как они управмяют преступностью». [14, p. 201] В целом поАхоА США к борьбе с терроризмом в большей мере характеризуется как военная операция, испомьзование силы и принуждения (операция возмезАия). [15, p. 459]
Европа, в отличие от США, в большей мере осознавая сложность и политическую обусловменность терроризма, склоняется к использованию полицейско-правовых и политических инструментов Аля борьбы с ним. [18] Агрессивная настойчивость США, их склонность к вооруженным акциям Европой воспринимается настороженно. Существующие разногласия хорошо осознаются и в Америке. Так, Ч. Фриман, оценивая эффективность внешней политики американского государства, пишет: «Европа сомневается в нашей рассудительности, заметно беспокоится из-за нашей воинственности и Аистанцируется от нашего мидерства... Угроза применения силы стала первым, а не последним средством во внешней политике. Мы, американцы, используем меры принуждения по умолчанию, оказывая давление на Аругие страны, будь они нашими союзниками, Арузьями, противниками или врагами». [12]

США ориентированы на киквидацию организационного яАра террористических организаций, полагая, что это повлечет за собой миквидацию всей террористической сети, прекращение терактов. Назаров И.А. на основе анализа основных вех американской истории антитеррористической борьбы делает вывоА что «американская внешняя политика в отношении межАународного терроризма строилась и продолжает базироваться на принципе уничтожения террористских организаций и режимов». [4, с. 12]

ПоАобный ПоАхоА ПреАставмяется сомнительным. Более того, имеется исторический опыт противодействия Израиля и Палестины, который свидетельствует, что уничтожение руководства оппозиции не стало Аля Израимя панацеей: места выбывших лидеров заняли новые лица. [19, p. 41]

В отношении понятия межАународного терроризма существуют принципиальные размичия межАу общеевропейским и американским поАходами. В США, в связи с милитаристско-помитизированным взглядом на Аанный феномен распространено максимально широкое, неконкретное представление, не позволяющее опреАелить четкие правовые рамки понятия. Американская Аоктрина считает криминальность терроризма Аишь оАним из эмементов, причем не ведущим, в его определении. ЕАиная Европа безусловно признает все формы терроризма преступмениями, требующими прежАе всего мер правового противодействия. [8]

Важно, что США склонны признавать госуАарственную версию терроризма, в то время как Европа не показывает очевиАной правовой воли 


\section{НАЦИОНААЬНАЯ БЕЗОПАСНОСТЬ • 5 (46) • 2016}

на закрепление этого понятия в антитеррористическом праве.

Таким образом, Объединенная Европа и США согласимись, что терроризм является вемичайшим вызовом межАународной безопасности, что это зАо может быть сокрушено мишь при опоре на многосторонние институты и межАународное право. ОАнако отметим, что правовое определение этого явцения так и не согласовано межАу ЕС и США. В обоих политико-правовых образованиях наблюАается разница в подходах к тактике и стратегии борьбы с ним, некоторая несогласованность Аоктринальных идей.

Все это позволяет саелать вывоА, что на Аанном этапе способы межАународного уча- стия США в контртеррористической борьбе носят оАносторонний, помитизированный характер. НАТО, вслеА за США, считает возможным вести борьбу с терроризмом военными, а не правовыми методами; в своих интересах, в одностороннем порядке, осуществлять антитеррористические операции на территории Аругих суверенных госуаарств, причем, нереАко в обход межАународно-правовых правиц. Показательно, что Ааже ближайшие союзники США - европейские страны, не согмасны с американской концепцией, в большей мере склонны считать терроризм - явлением уголовно-правового поряАка, чем вопросом политической борьбы госуАарственного уровня.

\section{БИБАИОГРАФИЯ}

1. Батюк В.И. МежАународное сообщество в борьбе с терроризмом: проблемы структуризации // Вестник Российского университета Аружбы народов. Серия: Политология. 2008. № 1. С. 5-19.

2. Аовгань Е.Ф. К вопросу о правомерности вооруженных антитеррористических мер в контексте принципа невмешательства во внутренние Аела государств // Беморусский журнал междунароАного права и межАународных отношений. Мн., 2003. № 3. С. 3-12.

3. ЕС за сотрудничество с США в борьбе с терроризмом // URL: [Электронный ресурс] http:// www.arms-expo.ru (Аата обращения 13.05.2015).

4. Назаров И.А. Эволюция американских концептуальных взглядов на природу международного терроризма и методы борьбы с ним (2001-2004 гг.): Аис. ... канА. ист. наук. М., 2007. 180 с.

5. НАТО и борьба с терроризмом. 27-Oct-2010 17:27 // URL: [Эмектронный ресурc] http://www. nato.int/cps/ru/natohq/topics_48801.htm (Аата обращения 13.05.2015)

6. Устав НATO. Североатлантический Аоговор // URL: [Электронный ресурс] Http:EurasianDefence.Ru/?Q=Node/3872 (Аата обращения 13.05.2015)

7. Aksoy E. International Terrorism in the Age of Globalization. Department of International Relations. Bilkent University. Ankara, 2002.90 p.

8. Council of the European Union Framework Decision on Combating Terrorism, 13 June 2002 (2002/475/JHA) // URL [Электронный ресурc]: http://europa.eu/legislation_summaries (Аата обращения 15.07.2015).

9. Draft resolution GA. Measures to eliminate international terrorism. Sixth Committee. Sixty-eighth session. Doc. A/C.6/68/L.13. 28 October 2013 // [Эмектронный ресурс] URL: http://www.un.org (Аата обращения 15.06.2015)

10. EU counter-terrorism policy// URL [Электронный ресурс]: http://europa.eu/legislation_summaries (Аата обращения 15.07.2015)

11. Framework Decision 2008/919/JHA, adopted on 28 November 2008. OJ L 330, 9.12.2008 // URL [Эмектронный ресурс]: http://europa.eu/legislation_summaries (Аата обращения 15.07.2015)

12. Freeman C. America's Diplomatic Crisis. June 16, 2015 // URL: [Электронный ресурс] www. teamamaricanconservative.com. (Аата обращения 16.07.2015)

13. Goldsmith J. The self-defeating International Criminal Court // The University of Chicago law review. Vol. 70. No. 1. 2003. P. 89-104.

14. Hamm M.S. Terrorism as Crime: From Oklahoma City to Al-Qaeda and Beyond. New York: New York University Press. 2007. 271 p.

15. Oliverio A US versus European Approaches to Terrorism: Size Really Does Matter// Policing. Vol. 2. Number 4. 2008. P. 452-462.

16. Sixth Committee Hears Working Group Reports, Approves Drafts on Programme Assistance, Measures To Eliminate International Terrorism. Sixth Committee. 28th Meeting (AM). Sixty-eighth General Assembly // URL: [Электронный ресурc] http://www.un.org (Аата обращения 16.07.2015) 
17. Text of U.S.-EU Declaration On Combating Terrorism. U.S.-EU Summit. Dromoland Castle. Shannon, Ireland. 26 June 2004 // URL: [ЭАектронный pecypc] http://www.state.gov/p/eur/rls/fs/36892. htm (Аата обращения 16.07.2015)

18. The EU Counter-Terrorism Policy: main achievements and future challenges Brussels, 20.7.2010. $\operatorname{COM}(2010) 386$ final. SEC(2010)911 // URL [Эмектронный pecypc]: http://eur-lex.europa.eu/ LexUriServ (Аата обращения 15.06.2015)

19. Yehuda Ben N. Terror, Media and Moral Boundaries // Terrorism: A New Testament. - Ontario, Canada: 2005. De Sitter. P. 39-64.

\section{REFERENCES (TRANSLITERATED)}

1. Batyuk V.I. Mezhdunarodnoe soobshchestvo v bor'be s terrorizmom: problemy strukturizatsii // Vestnik Rossiiskogo universiteta druzhby narodov. Seriya: Politologiya. 2008. № 1. S. 5-19.

2. Dovgan' E.F. K voprosu o pravomernosti vooruzhennykh antiterroristicheskikh mer $\mathrm{v}$ kontekste printsipa nevmeshatel'stva vo vnutrennie dela gosudarstv // Belorusskii zhurnal mezhdunarodnogo prava i mezhdunarodnykh otnoshenii. Mn., 2003. № 3. S. 3-12.

3. ES za sotrudnichestvo s SShA v bor'be s terrorizmom // URL: [Elektronnyi resurs] http://www.armsexpo.ru (Data obrashcheniya 13.05.2015).

4. Nazarov I.A. Evolyutsiya amerikanskikh kontseptual'nykh vzglyadov na prirodu mezhdunarodnogo terrorizma i metody bor' by s nim (2001-2004 gg.): dis. ... kand. ist. nauk. M., 2007. $180 \mathrm{~s}$.

5. NATO i bor'ba s terrorizmom. 27-Oct-2010 17:27 // URL: [Elektronnyi resurs] http://www.nato.int/ cps/ru/natohq/topics_48801.htm (Data obrashcheniya 13.05.2015)

6. Ustav NATO. Severoatlanticheskii Dogovor // URL: [Elektronnyi resurs] Http:Eurasian-Defence. $\mathrm{Ru} / ? \mathrm{Q}=$ Node/3872 (Data obrashcheniya 13.05.2015)

7. Aksoy E. International Terrorism in the Age of Globalization. Department of International Relations. Bilkent University. Ankara, 2002.90 r.

8. Council of the European Union Framework Decision on Combating Terrorism, 13 June 2002 (2002/475/JHA) // URL [Elektronnyi resurs]: http://europa.eu/legislation_summaries (Data obrashcheniya 15.07.2015).

9. Draft resolution GA. Measures to eliminate international terrorism. Sixth Committee. Sixty-eighth session. Doc. A/C.6/68/L.13. 28 October 2013 // [Elektronnyi resurs] URL: http://www.un.org (Data obrashcheniya 15.06.2015)

10. EU counter-terrorism policy // URL [Elektronnyi resurs]: http://europa.eu/legislation_summaries (Data obrashcheniya 15.07.2015)

11. Framework Decision 2008/919/JHA, adopted on 28 November 2008. OJ L 330, 9.12.2008 // URL [Elektronnyi resurs]: http://europa.eu/legislation_summaries (Data obrashcheniya 15.07.2015)

12. Freeman C. America's Diplomatic Crisis. June 16, 2015 // URL: [Elektronnyi resurs] www. teamamaricanconservative.com. (data obrashcheniya 16.07.2015)

13. Goldsmith J. The self-defeating International Criminal Court // The University of Chicago law review. Vol. 70. No. 1. 2003. R. 89-104.

14. Hamm M.S. Terrorism as Crime: From Oklahoma City to Al-Qaeda and Beyond. New York: New York University Press. 2007.271 p.

15. Oliverio A US versus European Approaches to Terrorism: Size Really Does Matter// Policing. Vol. 2. Number 4. 2008. P. 452-462.

16. Sixth Committee Hears Working Group Reports, Approves Drafts on Programme Assistance, Measures To Eliminate International Terrorism. Sixth Committee. 28th Meeting (AM). Sixty-eighth General Assembly // URL: [Elektronnyi resurs] http://www.un.org (data obrashcheniya 16.07.2015)

17. Text of U.S.-EU Declaration On Combating Terrorism. U.S.-EU Summit. Dromoland Castle. Shannon, Ireland. 26 June 2004 // URL: [Elektronnyi resurs] http://www.state.gov/p/eur/rls/fs/36892.htm (data obrashcheniya 16.07.2015)

18. The EU Counter-Terrorism Policy: main achievements and future challenges Brussels, 20.7.2010. $\operatorname{COM}(2010) 386$ final. SEC(2010)911 // URL [Elektronnyi resurs]: http://eur-lex.europa.eu/ LexUriServ (Data obrashcheniya 15.06.2015)

19. Yehuda Ben N. Terror, Media and Moral Boundaries // Terrorism: A New Testament. - Ontario, Canada: 2005. De Sitter. R. 39-64. 